\title{
PERHITUNGAN ASURANSI DANA PENSIUN DENGAN MENGGUNAKAN METODE PROJECTED UNIT CREDIT DAN METODE ENTRY AGE NORMAL PADA STATUS GABUNGAN
}

\author{
OSSI FAJRIA \\ Program Studi Matematika, \\ Fakultas Matematika dan Ilmu Pengetahuan Alam, Universitas Andalas, \\ Kampus UNAND Limau Manis Padang, Indonesia, \\ email : ossifajria@yahoo.com
}

\begin{abstract}
Abstrak. Asuransi dana pensiun merupakan salah satu upaya yang dapat dilakukan oleh pegawai untuk mengantisipasi masa pensiun yang cukup beresiko karena tidak lagi memiliki penghasilan yang tetap untuk kelangsungan hidupnya. Peserta asuransi dana pensiun dapat diikuti secara perorangan atau lebih (gabungan). Perhitungan asuransi dana pensiun gabungan dihitung dimulai dengan menentukan manfaat pensiun saat usia pensiun dan menentukan iuran normal. Besarnya iuran iuran normal dihitung dengan menggunakan metode perhitungan aktuaria pada asuransi dana pensiun. Pada penelitian ini peserta dari program asuransi dana pensiun adalah gabungan yaitu terdiri dari dua orang peserta yang berusia $x$ dan $y$ tahun. Penelitian ini bertujuan untuk mengetahui bagaimana perhitungan pembayaran iuran normal pada asuransi dana pensiun dengan menggunakan metode projected unit credit dan metode entry age normal untuk status gabungan. Pada metode projected unit credit besarnya iuran normal terus meningkat setiap tahun seiring bertambahnya usia peserta. Sedangkan menggunakan metode entry age normal besar iuran normal besarnya sama setiap tahunnya.
\end{abstract}

Kata Kunci: Asuransi Dana Pensiun, manfaat pensiun, iuran normal, metode Projected Unit Credit, metode Entry Age Normal

\section{Pendahuluan}

Pegawai atau karyawan adalah orang yang bekerja dengan menerima upah atau imbalan dalam bentuk lain. Kondisi dari pegawai atau karyawan yang memiliki batasan usia bekerja sesuai dengan kesepakatan dengan pihak pemberi kerja, ketika seorang pegawai sudah memasuki batas usia tersebut maka pegawai tersebut akan memasuki masa yang cukup beresiko karena tidak lagi bekerja dan memiliki penghasilan yang tetap dan dapat mengancam kelangsungan hidup dari pegawai tersebut. Masa tersebut disebut dengan masa pensiun. Untuk mengantisipasi risiko tersebut maka karyawan tersebut mengikuti asuransi dana pensiun yang bertujuan untuk membentuk sejumlah dana agar dapat digunakan setelah memasuki usia pensiun. Asuransi dana pensiun dapat diikuti secara perorangan dan gabungan dari beberapa peserta asuransi.

Pada asuransi dana pensiun terdapat kesepakatan antara peserta asuransi dana pensiun dengan pihak pengelola asuransi dana pensiun yaitu besarnya iuran normal 
yang dibayarkan oleh peserta untuk mendapatkan manfaat pensiun saat mencapai usia pensiun. Iuran normal dapat dihitung menggunakan metode perhitungan aktuaria [1]. Metode penghitungan aktuaria dibagi menjadi dua kategori besar, yaitu metode accrued benefit cost dan metode projected benefit cost. Metode yang termasuk dalam metode accrued benefit cost adalah metode projected unit credit, dan metode yang termasuk dalam metode projected benefit cost adalah metode entry age normal. Metode projected unit credit adalah membagi total manfaat pensiun pada usia pensiun dengan total masa kerja menjadi satuan unit manfaat pensiun yang kemudian dialokasikan ke setiap tahun selama masa kerja, sedangkan Metode entry age normal merupakan metode pendanaan yang perhitungannya berdasarkan usia peserta saat pertama kali masuk kerja sampai usia pensiun. Pada status gabungan ini manfaat pensiun yang diterima oleh peserta ketika salah satu dari peserta asuransi dana pensiun mencapai usia pensiun dan pembayaran iuran normal akan berhenti.

Pada penelitian ini akan dibahas perhitungan asuransi dana pensiun dengan menggunakan metode projected unit credit dan metode entry age normal untuk status gabungan dari dua peserta asuransi dana pensiun. Perhitungan dimulai dengan menghitung besarnya manfaat pensiun dan selanjutnya menghitung iuran normal dari masing-masing metode yang digunakan. Penggunaan asumsi tingkat kenaikan gaji sama setiap tahunnya, sedangkan kebijakan pemerintah dianggap tidak ada serta golongan dari peserta program dana pensiun masuk sampai pensiun diasumsikan sama.

\section{Fungsi Dasar Perhitungan Aktuaria}

Fungsi-fungsi dasar aktuaria yang digunakan antara lain fungsi kelangsungan hidup, fungsi tingkat suku bunga, fungsi gaji dan fungsi manfaat [3].

1. Fungsi Kelangsungan Hidup.

Fungsi kelangsungan hidup menunjukan peluang seorang karyawan akan tetap bekerja selama masa kerja aktif sampai waktu yang diperbolehkan untuk pensiun. Dirumuskan dengan

$$
{ }_{t} p_{x}=\frac{l_{x+t}}{l_{x}} .
$$

2. Fungsi Tingkat Suku Bunga.

Fungsi tingkat suku bunga digunakan untuk mendiskontokan suatu pembayaran yang akan datang ke waktu sekarang. Jika $i$ adalah tingkat suku bunga untuk $t$ tahun, dengan $t=1,2, \cdots, n$ dan besar $i$ tidak berubah setiap tahunnya, maka:

$$
v^{n}=\frac{1}{(1+i)^{n}}, \text { dimana }
$$

$v^{n}$ adalah nilai sekarang dari pembayaran sebesar 1 satuan yang dilakukan selama $n$ tahun mendatang.

3. Fungsi Gaji.

Besarnya gaji untuk peserta berusia $x$ tahun dilambangkan dengan $s_{x}$. Jika diasumsikan besarnya tingkat kenaikan gaji karyawan adalah $c \%$ pertahun, 
besar gaji karyawan pada usia $x+t$ tahun berdasarkan gaji pada usia $x$ tahun adalah

$$
s_{x+t}=s_{x}(1+c)^{t}
$$

4. Fungsi Manfaat.

Fungsi manfaat digunakan untuk menentukan jumlah manfaat yang dibayarkan pada saat pensiun dipercepat (keluar), kematian, pensiun karena tidak bisa bekerja (cacat), atau pensiun pada saat usia pensiun. Manfaat yang diterima oleh peserta program dana pensiun merupakan proporsi gaji sebesar $k$ persen yang kemudian diakumulasikan sesuai waktu yang telah ditentukan selama ( $r-$ e) dan berdasarkan skala gaji berikut:

a. Asumsi Gaji Terakhir.

Besar manfaat pensiun pada usia $r$ tahun adalah:

$$
B_{r}=k(r-e) s_{r-1} .
$$

b. Asumsi Rata-Rata Gaji Selama Bekerja.

Besar manfaat pensiun pada usia $r$ tahun adalah:

$$
B_{r}=\left.k s_{x}(1+c)^{e-x} s_{r-e}\right|_{c} .
$$

c. Asumsi Rata-Rata Gaji Selama $n$ Tahun Terakhir. Besar manfaat pensiun pada usia $r$ tahun adalah:

$$
B_{r}=k(r-e) \frac{1}{n} \sum_{t=r-n}^{r-1} s_{t}(1+c)^{t} .
$$

5. Anuitas Hidup Gabungan.

Anuitas gabungan adalah suatu rangkaian pembayaran oleh dua orang peserta program dana pensiun atau lebih, dimana pembayaran terhenti apabila salah satu peserta program dana pensiun telah mencapai usia pensiun. Anuitas hidup yang digunakan yaitu anuitas awal seumur hidup dan anuitas awal berjangka.

Nilai sekarang anuitas awal seumur hidup adalah nilai sekarang suatu anuitas hidup yang mana pembayarannya dilakukan pada setiap awal periode selama peserta program dana pensiun belum mencapai usia pensiun, dalam hal ini peserta program dana pensiun berusia $x$ dan $y$ tahun. Maka nilai sekarang anuitas awal gabungan seumur hidup dinyatakan dengan [2]:

$$
\ddot{a}_{x y}=\frac{N_{x y}}{D_{x y}}
$$

Nilai sekarang anuitas hidup awal gabungan berjangka merupakan nilai sekarang suatu anuitas hidup gabungan yang mana pembayarannya dilakukan tiap awal periode selama $n$ tahun dari peserta berusia $x$ dan $y$ tahun. Pembayaran akan terhenti jika salah satu peserta program dana pensiun mencapai usia pensiun dalam jangka waktu $n$ tahun. Maka nilai sekarang anuitas awal berjangka gabungan dinyatakan dengan [2]:

$$
\ddot{a}_{x y: \bar{n} \mid}=\frac{N_{x y}-N_{x+n: y+n}}{D_{x y}}
$$




\section{Manfaat Pensiun Gabungan}

Manfaat pensiun adalah besarnya pembayaran secara berkala yang dibayarkan oleh pengelola asuransi dana pensiun kepada peserta saat memasuki usia pensiun. Besarnya manfaat pensiun dapat dihitung dengan menggunakan fungsi manfaat pada fungsi dasar aktuaria. Fungsi manfaat yang digunakan yaitu berdasarkan gaji terakhir yang diterima oleh masing-masing peserta sebelum memasuki usia pensiun.

Besarnya nilai manfaat gabungan dari peserta program dana pensiun yang berusia $x$ dan berusia $y$ tahun dapat ditentukan dengan menjumlahkan nilai manfaat pensiun dari masing-masing peserta program dana pensiun. Misalkan $r$ adalah usia pensiun dari peserta program dana pensiun, $S_{r(x)-1}$ dan $S_{r(y)-1}$ dinyatakan sebagai gaji terakhir dari peserta program dana pensiun yang berusia $x$ dan $y$ tahun, $e_{(x)}$ adalah usia awal masuk kerja untuk peserta yang berusia $x$ tahun dan $e_{(y)}$ adalah usia awal masuk kerja untuk peserta yang berusia $y$ tahun, $k$ adalah notasi dari proporsi gaji yang diberikan untuk besar nilai manfaat, maka besar nilai manfaat pensiun gabungan berdasarkan gaji terakhir untuk peserta program dana pensiun berusia $x$ dan $y$ tahun adalah

$$
\begin{aligned}
B_{r r} & =B_{r(x)}+B_{r(y)} \\
& =\left(k\left(r-e_{(x)}\right) S_{r(x)-1}\right)+\left(k\left(r-e_{(y)}\right) S_{r(y)-1}\right) .
\end{aligned}
$$

Nilai sekarang dari manfaat pensiun gabungan atau present value of future benefit ( $P V F B$ ) gabungan adalah nilai sekarang dari besarnya manfaat pensiun gabungan yang akan diterima oleh peserta program dana pensiun gabungan saat usia pensiun. Maka nilai sekarang dari manfaat pensiun gabungan dari peserta yang berusia $x$ dan $y$ tahun serta memiliki usia pensiun sama yaitu $r$ tahun dirumuskan dengan

$$
{ }^{r r}(P V F B)_{x y}=B_{r r} \ddot{a}_{r r} \frac{D_{r r}}{D_{x y}} .
$$

\section{Iuran Normal Gabungan}

Iuran normal adalah iuran yang diperlukan dalam satu tahun untuk mendanai bagian dari nilai sekarang manfaat pensiun yang dialokasikan pada tahun yang bersangkutan.

1. Iuran Normal Dengan Metode Projected Unit Credit.

Iuran normal gabungan dengan metode Projected Unit Credit dari peserta berusia $x$ dan $y$ tahun yang memiliki usia pensiun sama yaitu $r$ tahun dinyatakan dengan:

$$
{ }^{r r}(N C)_{x y}=\left(\frac{1}{r_{(x)}-e_{(x)}}+\frac{1}{r_{(y)}-e_{(y)}}\right){ }^{r r}(P V F B)_{x y} .
$$

2. Iuran Normal Dengan Metode Entry Age Normal.

Iuran normal gabungan dengan metode entry age normal dari peserta berusia $x$ dan $y$ tahun dengan usia masuk kerja masing-masing $e_{(x)}$ dan $e_{(y)}$ tahun dan 
usia pensiun sama yaitu $r$ tahun dinyatakan dengan

$$
{ }^{r r}(N C)_{e_{x} e_{y}}=\frac{r r(P V F B)_{e_{x} e_{y}}}{\ddot{a}_{e_{x} e_{y}: \overline{n \mid}}} .
$$

\section{Ilustrasi Kasus}

Seorang pegawai berjenis kelamin laki-laki diangkat menjadi pegawai pada usia 27 tahun $\left(e_{(x)}=27\right)$ dan mulai terhitung pensiun pada usia 58 tahun $(r=58)$. Gaji pokok yang diterima pada tahun pertama adalah sebesar Rp. 1.655.800,00 dan diasumsikan meningkat sebesar $7 \%(c=7 \%)$ pertahun dari gaji pokok tahun pertama yang didapatkan.

Kemudian seorang pegawai berjenis kelamin perempuan diangkat menjadi pegawai pada usia 25 tahun $\left(e_{(y)}=25\right)$ dan mulai terhitung pensiun pada usia 58 tahun $(r=58)$. Besar gaji pokok yang diterima pada tahun pertama adalah sebesar Rp. 1.743.400,00 dan diasumsikan meningkat sebesar 7\% $(c=7 \%)$ pertahun dari gaji pokok tahun pertama yang didapatkan.

Misalkan dua orang pegawai tersebut terdaftar sebagai peserta program asuransi dana pensiun untuk status gabungan. Perhitungan dilakukan pada saat awal peserta terdaftar program asuransi dana pensiun, untuk peserta pertama berusia 27 tahun $(x=27)$ dan peserta kedua berusia 25 tahun $(y=25)$. Setelah dilakukan perhitungan diperoleh

1. Anuitas awal seumur hidup gabungan dari peserta $x=27$ dan $y=25$ tahun yaitu $\ddot{a}_{58,58}=7,809989437$.

2. Anuitas awal berjangka gabungan dari peserta $x=27$ dan $y=25$ tahun dengan pembayaran selama $n=31$ tahun yaitu $\ddot{a}_{27,25: \overline{31 \mid}}=10,16199193$.

3. Besar manfaat pensiun gabungan. Sebelum menghitung besar manfaat pensiun dihitung terlebih dahulu besar gaji yang diterima setiap tahun mulai dari masuk kerja sampai mencapai usia pensiun dari masing-masing peserta $x$ dan $y$. Besaran gaji $(x)$ dan $(y)$ dapat dilihat pada Gambar 1. Berdasarkan gaji yang didapatkan oleh masing-masing peserta, diperoleh besar manfaat gabungan dari kedua peserta adalah $B_{58,58}=R p .22 .303 .605,78$.

4. Nilai sekarang dari manfaat pensiun dari peserta $x$ dan $y$ adalah sebesar ${ }_{58,58}(\text { PVFB })_{27,25}=$ Rp. 6.699.757, 245.

5. Iuran normal dengan menggunakan metode projected unit credit dari peserta berusia $x$ dan $y$ tahun adalah sebesar ${ }^{58,58}(N C)_{27,25}=R p .419 .144,1484$.

6. Iuran normal dengan menggunakan metode entry age normal dari peserta berusia $x$ dan $y$ tahun adalah sebesar ${ }^{58,58}(N C)_{27,25}=R p .659 .295,6668$.

\section{Kesimpulan}

Pada paper ini dibahas tentang perhitungan asuransi dana pensiun dengan metode projected unit credit dan metode entry age normal pada status gabungan dengan langkah-langkah sebagai berikut 


\begin{tabular}{|c|c|c|}
\hline $\mathbf{t}$ & $\mathbf{x}$ & $\mathbf{S}(\mathbf{x}+\mathbf{t})$ \\
\hline 0 & 27 & $R p 1.655 .800$ \\
\hline 1 & 28 & $R p 1.771 .706$ \\
\hline 2 & 29 & $R p 1.895 .725$ \\
\hline 3 & 30 & $R p 2.028 .426$ \\
\hline 4 & 31 & $R p 2.170 .416$ \\
\hline 5 & 32 & $R p 2.322 .345$ \\
\hline 6 & 33 & $R p 2.484 .909$ \\
\hline 7 & 34 & $R p 2.658 .853$ \\
\hline 8 & 35 & $R p 2.844 .973$ \\
\hline 9 & 36 & $R p 3.044 .121$ \\
\hline 10 & 37 & $R p 3.257 .209$ \\
\hline
\end{tabular}

\begin{tabular}{|c|c|c|}
\hline$t$ & $x$ & $S(x+t)$ \\
\hline 11 & 38 & $R p 3.485 .214$ \\
\hline 12 & 39 & $R p 3.729 .179$ \\
\hline 13 & 40 & $R p 3.990 .221$ \\
\hline 14 & 41 & $R p 4.269 .537$ \\
\hline 15 & 42 & $R p 4.568 .404$ \\
\hline 16 & 43 & $R p 4.888 .193$ \\
\hline 17 & 44 & $R p 5.230 .366$ \\
\hline 18 & 45 & $R p 5.596 .492$ \\
\hline 19 & 46 & $R p 5.988 .246$ \\
\hline 20 & 47 & $R p 6.407 .424$ \\
\hline 21 & 48 & $R p 6.855 .943$ \\
\hline
\end{tabular}

\begin{tabular}{|c|c|c|}
\hline $\mathbf{t}$ & $\mathbf{x}$ & $\mathrm{S}(\mathbf{x}+\mathbf{t})$ \\
\hline 22 & 49 & $R p 7.335 .859$ \\
\hline 23 & 50 & $R p 7.849 .369$ \\
\hline 24 & 51 & $R p 8.398 .825$ \\
\hline 25 & 52 & $R p 8.986 .743$ \\
\hline 26 & 53 & $R p 9.615 .815$ \\
\hline 27 & 54 & $R p 10.288 .922$ \\
\hline 28 & 55 & $R p 11.009 .147$ \\
\hline 29 & 56 & $R p 11.779 .787$ \\
\hline 30 & 57 & $R p 12.604 .372$ \\
\hline
\end{tabular}

\begin{tabular}{|c|c|c|}
\hline$t$ & $y$ & $S(y+t)$ \\
\hline 0 & 25 & $R p 1.743 .400$ \\
\hline 1 & 26 & $R p 1.865 .438$ \\
\hline 2 & 27 & $R p 1.996 .019$ \\
\hline 3 & 28 & $R p 2.135 .740$ \\
\hline 4 & 29 & $R p 2.285 .242$ \\
\hline 5 & 30 & $R p 2.445 .209$ \\
\hline 6 & 31 & $R p 2.616 .373$ \\
\hline 7 & 32 & $R p 2.799 .519$ \\
\hline 8 & 33 & $R p 2.995 .486$ \\
\hline 9 & 34 & $R p 3.205 .170$ \\
\hline 10 & 35 & $R p 3.429 .532$ \\
\hline
\end{tabular}

\begin{tabular}{|l|l|l|}
\hline$t$ & $y$ & $s(y+t)$ \\
\hline
\end{tabular}

\begin{tabular}{|l|l|l|}
\hline$t$ & $y$ & $S(y+t)$ \\
\hline
\end{tabular}

\begin{tabular}{|l|l|l|l|l|l|l|}
\hline 11 & 36 & Rp3.669.599 \\
\hline 22 & 47 & Rp7.723.962 \\
\hline
\end{tabular}

\begin{tabular}{|l|l|l|l|l|l|}
\hline 12 & 37 & $R p 3.926 .471$ & 23 & 48 & $R p 8.264 .640$ \\
\hline
\end{tabular}

\begin{tabular}{|l|l|l|}
\hline 13 & 38 & Rp4.201.324 \\
\hline
\end{tabular}

\begin{tabular}{|l|l|l|}
\hline 14 & 39 & Rp4.495.416 \\
\hline
\end{tabular}

\begin{tabular}{|l|l|l|}
\hline 15 & 40 & Rp4.810.096 \\
\hline
\end{tabular}

\begin{tabular}{|l|l|l|}
\hline 16 & 41 & $R p 5.146 .802$ \\
\hline
\end{tabular}

\begin{tabular}{|l|l|l|}
\hline 17 & 42 & $R p 5.507 .078$ \\
\hline
\end{tabular}

\begin{tabular}{|l|l|l|}
\hline 18 & 43 & Rp5.892.574 \\
\hline
\end{tabular}

\begin{tabular}{|l|l|l|}
\hline 19 & 44 & $R p 6.305 .054$ \\
\hline
\end{tabular}

\begin{tabular}{|l|l|l|}
\hline 20 & 45 & Rp6.746.408 \\
\hline
\end{tabular}

\begin{tabular}{|l|l|l|}
\hline 24 & 49 & Rp8.843.165 \\
\hline
\end{tabular}

\begin{tabular}{|l|l|l|}
\hline 25 & 50 & $R p 9.462 .186$ \\
\hline
\end{tabular}

\begin{tabular}{|l|l|l|}
\hline 26 & 51 & Rp10.124.539 \\
\hline
\end{tabular}

\begin{tabular}{|l|l|l|}
\hline 27 & 52 & Rp10.833.257 \\
\hline
\end{tabular}

\begin{tabular}{|l|l|l|}
\hline 28 & 53 & Rp11.591.585 \\
\hline
\end{tabular}

\begin{tabular}{|l|l|l|}
\hline 29 & 54 & Rp12.402.996 \\
\hline
\end{tabular}

\begin{tabular}{|l|l|l|}
\hline 30 & 55 & Rp13.271.205 \\
\hline
\end{tabular}

\begin{tabular}{|l|l|l|}
\hline 31 & 56 & Rp14.200.190 \\
\hline
\end{tabular}

\begin{tabular}{|l|l|l|l|}
\hline 21 & 46 & Rp7.218.656 \\
\hline 32 & 57 & Rp15.194.203 \\
\hline
\end{tabular}

Gambar 1. Besar gaji peserta program dana pensiun laki-laki $(x)$ dan perempuan $(y)$ pada tahun pertama sampai memasuki usia pensiun

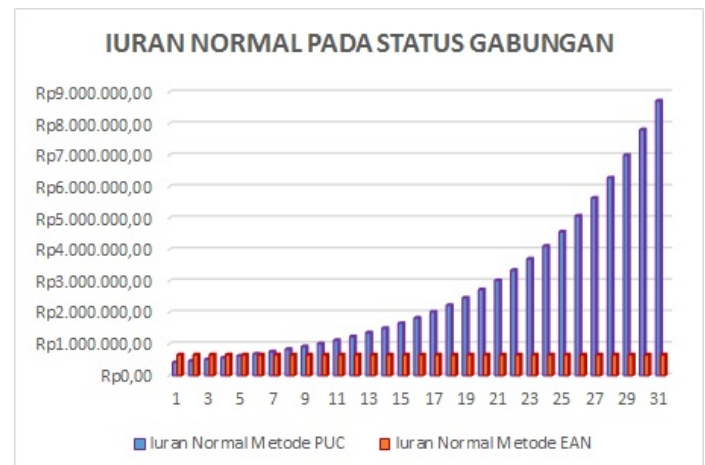

Gambar 2. Besar iuran normal pada status gabungan dengan metode projected unit credit dan metode entry age normal

(1) Iuran normal yang dibayarkan setiap tahun oleh peserta program dana pensiun dipengaruhi oleh peluang hidup dan nilai sekarang dari anuitas hidup. Sementara itu besar gaji dan usia masuk kerja peserta juga mempengaruhi nilai manfaat pensiun dan iuran normal yang harus dibayarkan oleh peserta program dana pensiun. Semakin besar gaji pokok dari peserta program dana pensiun 
maka semakin besar juga nilai manfaat yang diperolehnya dimasa pensiun.

(2) Pada metode projected unit credit besarnya iuran normal akan mengalami peningkatan setiap tahunnya seiring dengan pertambahan usia peserta. Semakin bertambahnya usia peserta program dana pensiun maka semakin besar pula iuran normal yang dibayarkan oleh peserta program dana pensiun. Pasa metode entry age normal besarnya iuran normal bernilai tetap atau konstan mulai dari awal masuk bekerja sampai memasuki usia pensiun.

\section{Daftar Pustaka}

[1] Aitken, W.H. 1994. A Problem Solving Approach to Pension Funding and Valuation, $2^{\text {nd }}$ edition. Winsted: Actex.

[2] Larson, R.E. dan E.A. Gaumnitz. 1962. Life Insurance Mathematics. New York: John Wiley and Sons Inc.

[3] Winklevoss, H.E. 1993. Pension Mathematics with Numerical Illustrations, $2^{\text {rd }}$ edition. Pension Research Council. USA. 